\title{
Src kinase activity coordinates cell adhesion and spreading with activation of mammalian target of rapamycin in pancreatic endocrine tumour cells
}

\author{
Alessia Di Florio ${ }^{1,2,3}$, Laura Adesso 1,2,3, Simona Pedrotti ${ }^{1,2}$, Gabriele Capurso ${ }^{3}$, \\ Emanuela Pilozzi ${ }^{4}$, Vincenzo Corbo ${ }^{5,6}$, Aldo Scarpa ${ }^{5,6}$, Raffaele Geremia ${ }^{1}$, \\ Gianfranco Delle Fave ${ }^{3}$ and Claudio Sette ${ }^{1,2}$
}

\footnotetext{
${ }^{1}$ Department of Public Health and Cell Biology, University of Rome Tor Vergata, Via Montpellier 1, 00133 Rome, Italy

${ }^{2}$ Laboratory of Neuroembryology, CERC Fondazione Santa Lucia, Rome, Italy

${ }^{3}$ Digestive and Liver Disease Unit and ${ }^{4}$ Department of Clinical and Molecular Medicine, II Medical School, University of Rome La Sapienza, Rome, Italy

${ }^{5}$ ARC-NET Research Center and ${ }^{6}$ Department of Pathology, University Hospital of Verona, Verona, Italy

(Correspondence should be addressed to C Sette at Department of Public Health and Cell Biology, University of Rome Tor Vergata; Email: claudio.sette@uniroma2.it; G Delle Fave; Email: gianfranco.dellefave@uniroma1.it)
}

\begin{abstract}
Pancreatic endocrine tumours (PETs) are rare and heterogeneous neoplasms, often diagnosed at metastatic stage, for which no cure is currently available. Recently, activation of two pathways that support proliferation and invasiveness of cancer cells, the Src family kinase (SFK) and mammalian target of rapamycin (mTOR) pathways, was demonstrated in PETs. Since both pathways represent suitable targets for therapeutic intervention, we investigated their possible interaction in PETs. Western blot and immunofluorescence analyses indicated that SFK and mTOR activity correlate in PET cell lines. We also found that SFKs coordinate cell adhesion and spreading with activation of the mTOR pathway in PET cells. Live cell metabolic labelling and biochemical studies demonstrated that SFK activity enhance mTOR-dependent translation initiation. Furthermore, microarray analysis of the mRNAs associated with polyribosomes revealed that SFKs regulate mTOR-dependent translation of specific transcripts, with an enrichment in mRNAs encoding cell cycle proteins. Importantly, a synergic inhibition of proliferation was observed in PET cells concomitantly treated with SFK and mTOR inhibitors, without activation of the phosphatidylinositol 3-kinase/AKT pro-survival pathway. Tissue microarray analysis revealed activation of Src and mTOR in some PET samples, and identified phosphorylation of 4E-BP1 as an independent marker of poor prognosis in PETs. Thus, our work highlights a novel link between the SFK and mTOR pathways, which regulate the translation of mRNAs for cell cycle regulators, and suggest that crosstalk between these pathways promotes PET cell proliferation.
\end{abstract}

Endocrine-Related Cancer (2011) 18 541-554

\section{Introduction}

Pancreatic endocrine tumours (PETs) are heterogeneous neoplasms in terms of histological features, tumour behaviour and clinical picture (Metz \& Jensen 2008). Although PETs are generally considered rare neoplasms, their incidence has almost doubled in the last 20 years (Fitzgerald et al. 2008). PETs represent $\sim 1 \%$ of all pancreatic cancers by incidence, but $10 \%$ by prevalence (Yao et al. 2007), and are one of the most challenging forms of neuroendocrine tumours (NETs), with a worse prognosis compared with gastrointestinal carcinoids (Panzuto et al. 2005). Most PETs present with metastases at diagnosis and are not amenable for surgery, which remains the only curative therapeutic approach. Medical treatments with somatostatin analogues and genotoxic agents are 
currently in use for PETs that cannot be approached by surgery, due to advanced locoregional disease or metastases. However, the efficacy of somatostatin analogues in inhibiting tumour growth is limited (Panzuto et al. 2006), whereas traditional genotoxic agents are not the ideal therapy for PETs because of their generally low proliferation rate. In this scenario, new strategies are required to face the therapeutic challenge represented by well-differentiated progressive, advanced PETs and novel 'targeted' approaches are under evaluation (Capurso et al. 2009).

Members of the Src family kinases (SFKs) are overexpressed in progressive, advanced PETs (Capurso et al. 2006), setting the ground for further investigation of these kinases in PET cells. SFKs are non-receptor tyrosine kinases activated in response to mitogenic stimuli. SFKs regulate cell proliferation, adhesion and motility (Frame et al. 2002, Bromann et al. 2004), and are frequently activated in human cancers, contributing to their malignancy and metastatic phenotype (Mao et al. 1997, Paronetto et al. 2004, Koliopanos et al. 2008). Importantly, Src is highly expressed in PETs, and its inhibition strongly impairs PET cell adhesion, spreading and migration (Di Florio et al. 2007).

SFKs translocate from perinuclear sites to the cell periphery in response to various stimuli. They interact with and phosphorylate proteins involved in remodelling of podosomes, lamellipodia and focal adhesion, thereby directly regulating cell attachment to the matrix and spreading (Frame et al. 2002). Adhesion also sets in motion other processes that are likely required to support cell proliferation or survival in the new environment. For instance, it induces mRNA translation through activation of the mammalian target of rapamycin (mTOR) serine/threonine kinase (Gorrini et al. 2005). However, whether adhesion-induced activation of protein synthesis relies on SFKs and if it promotes cancer cell proliferation or invasion is currently unknown.

mTOR plays a critical role in signalling pathways triggered by activation of phosphatidylinositol 3-kinase (PI3K) and protein kinase B (AKT), thereby regulating cell growth and death (Averous \& Proud 2006). mTOR is frequently activated in cancer cells and several oncogenes, such as PI3K and AKT, or tumour suppressors, such as PTEN, NF1A, LKB1 and the TSC1/TSC2 complex, rely on regulation of mTOR activity for cell transformation (Meric-Bernstam \& Gonzalez-Angulo 2009). The oncogenic activity of mTOR involves its role in protein synthesis, through phosphorylation of substrates required for ribosomal biosynthesis and mRNA translation, such as the ribosomal S6 kinase (S6K), the translation initiation factor eIF4B and the translation inhibitor 4E-BP1 (Hay \& Sonenberg 2004). The implication of mTOR in proliferation control has stimulated studies aimed at interfering with its activity in cancer cells (MericBernstam \& Gonzalez-Angulo 2009). Importantly, NETs are among the diseases for which mTOR targeting seems promising, as suggested by the relationship existing between alterations in the mTOR pathway and development or prognosis of NETs (Capurso et al. 2009, Missiaglia et al. 2010, Jiao et al. 2011).

In this study, we have investigated the possible link between the SFK and mTOR pathways in PETs. We found that activation of Src during cell adhesion stimulates mTOR activity, protein synthesis and translation of mRNAs for cell cycle proteins. Importantly, pharmacological inhibition of mTOR caused activation of Src, whereas concomitant inhibition of SFKs and mTOR activities exerted a synergistic effect on PET cell proliferation. These results suggest an interesting link between these pathways in the regulation of PET cell growth.

\section{Materials and methods}

\section{Cell culture and transfection}

QGP-1 and CM cells were grown as described (Di Florio et al. 2007). BON-1 cells were grown in DMEM-F12K (1:1) with 10\% FBS. HEK293T were grown in DMEM supplemented with $10 \%$ FBS. pEGFP-Src wild-type (WT) and kinase-dead (KD) vectors were obtained by subcloning the EcoRI/BamHI Src fragment from $\mathrm{pSGT}-\mathrm{SrcKD}$ and $\mathrm{pSGT}-\mathrm{SrcWT}$ in pEGFP C1 (Clontech). Transfections were performed by lipofectamine 2000 (Invitrogen). 300 pmol of SMART POOL siRNA for Src or control siRNAs (Dharmacon RNA Technologies, Lafayette, CO, USA) were transfected using Oligofectamine (Invitrogen).

\section{Protein extraction from tissue samples}

Freshly frozen tissue blocks of PET samples (primary lesions) from six patients undergoing surgery were obtained from the Pathology Unit, University of Verona, after ethics approval. After histological evaluation, tissues with neoplastic cellularity $>80 \%$ were employed. Subsequent sections from the same frozen tissue were left unstained and used for protein extraction using the AllPrep DNA/RNA/Protein mini Kit (Qiagen). As controls, proteins were also extracted from the pancreatic adenocarcinoma cell line PSN1 (Moore et al. 2001) and from a normal pancreas. 


\section{Polysome separation and extraction of RNA}

Cell extracts were prepared as described (Paronetto et al. 2006). An aliquot of each fresh lysate was used for western blot analysis and an aliquot was extracted with TRIZOL (Invitrogen) as a source of total RNA. The remaining extracts were loaded onto a $15-50 \%$ linear sucrose gradient (Paronetto et al. 2006). After ultracentrifugation, gradients were collected in ten fractions of $1 \mathrm{ml}$ each, starting from the bottom. Fractions 1-4, containing the polyribosomes, were pooled for subsequent analyses. RNA was isolated with RNeasy Mini Kit (Qiagen), diluted in RNase-free water (Sigma-Aldrich) and immediately frozen at $-80{ }^{\circ} \mathrm{C}$ for further analysis.

\section{GeArray cancer biomarkers}

Polysomal RNA was used as template to generate biotin16-UTP-labelled cRNA probes using the True Labelling Kit (Superarray, Inc., Bethesda, MD, USA). The cRNA probes were hybridised at $60^{\circ} \mathrm{C}$ with the SuperArray Cancer Biomarkers membranes and signals were revealed using the SuperArray Detection Kit. Data were analysed by densitometry using the Scanalyze Software and following the manufacturer's instruction (Stanford Computer Graphics Laboratory, Stanford, CA, USA).

\section{$m^{7}$ GTP-sepharose chromatography}

Cell extracts were prepared as described (Bianchini et al. 2008) and incubated for $2 \mathrm{~h}$ at $4{ }^{\circ} \mathrm{C}$ with 7-methyl-GTP sepharose (Amersham) under constant shaking. Beads were washed three times with lysis buffer and absorbed proteins were eluted in SDS-PAGE sample buffer.

\section{Immunofluorescence analysis}

PET cells were processed for indirect immunofluorescence analysis as described previously (Paronetto et al. 2006), using $\alpha$-phalloidin antibody (1:200, SigmaAldrich), rabbit $\alpha$-Src antibody (1:50; Santa Cruz, Milan, Italy), rabbit $\alpha$-pSer235/236 rpS6 and rabbit $\alpha$-pSer45 4E-BP1 (1:100; Cell Signalling, Danvers, MA, USA) and, as secondary antibodies, with FITCconjugated donkey anti-rabbit (1:200); cy3-conjugated donkey anti-rabbit (1:100; Jackson Immunoresearch, Bar Harbor, ME, USA). Hoechst dye $(0.1 \mathrm{mg} / \mathrm{ml}$; Sigma-Aldrich) was added for the last $10 \mathrm{~min}$. Slides were mounted in Mowiol 4-88 (Calbiochem, Darmstadt, Germany).

\section{Immunohistochemistry}

Immunohistochemistry (IHC) was performed on a paraffin-embedded tissue microarray (TMA) containing 31 primary non-functioning, resected PETs and two normal pancreas samples spotted in triplicate, as described previously (Missiaglia et al. 2010). Detailed clinical and histopathological data for each patient had been recorded in a dedicated electronic database (Missiaglia et al. 2010). The antibodies used were: 4E-BP1 (53H11, 1:1000), phosphorylated 4E-BP1 (p-4E-BP1) Thr37/46 (236B4, 1:500), Src (1:50) and phosphorylated Src (p-Src) Tyr 416 (1:100; all from Cell Signalling). Samples were scored positive if any staining was observed. Based on the percentage of positive cells two groups were identified: $\leq 10 \%$ (group A) or $>10 \%$ (group B). For 4E-BP1 and $\mathrm{p}-4 \mathrm{E}-\mathrm{BP} 1$ nuclear and cytoplasmic staining was evaluated.

Statistical analysis of IHC results was performed by MedCalc 9.6 (www.medcalc.be). Differences for continuous variables were evaluated by $t$-test and for categorical variables by Fisher's test. Correlation between the IHC expression scores and clinicopathological data (such as proliferation index) was tested by Spearman's rank order correlation. Analysis of overall survival was performed by Kaplan-Meier method and analysed by log-rank test. Univariate and multivariate analyses for risk factors affecting survival was performed by Cox proportional-hazards regression model test; a $P$ value $<0.05$ was considered statistically significant.

Additional experimental procedures are described in the Supplementary Tables 1 and 2, see section on supplementary data given at the end of this article.

\section{Results}

\section{SFKs modulate mTOR activity in PET cell lines}

To test whether a correlation exists between SFK and mTOR activity in PET cell lines, we examined the phosphorylation status of relevant proteins in their pathways. Phosphorylation of Src in tyrosine 416, which correlates with its activation, was higher in QGP-1 and BON-1 cells with respect to CM cells (Fig. 1A). For the mTOR pathway, we calculated by densitometry the ratio between phosphorylated versus total protein for 4E-BP1, a direct mTOR substrate, and ribosomal protein $\mathrm{rpS6}$, an indirect mTOR target (Hay \& Sonenberg 2004). Interestingly, we found that the phosphorylation status of both 4E-BP1 and rpS6 was also higher in QGP-1 and BON-1 cells than in CM cells (Fig. 1A). 


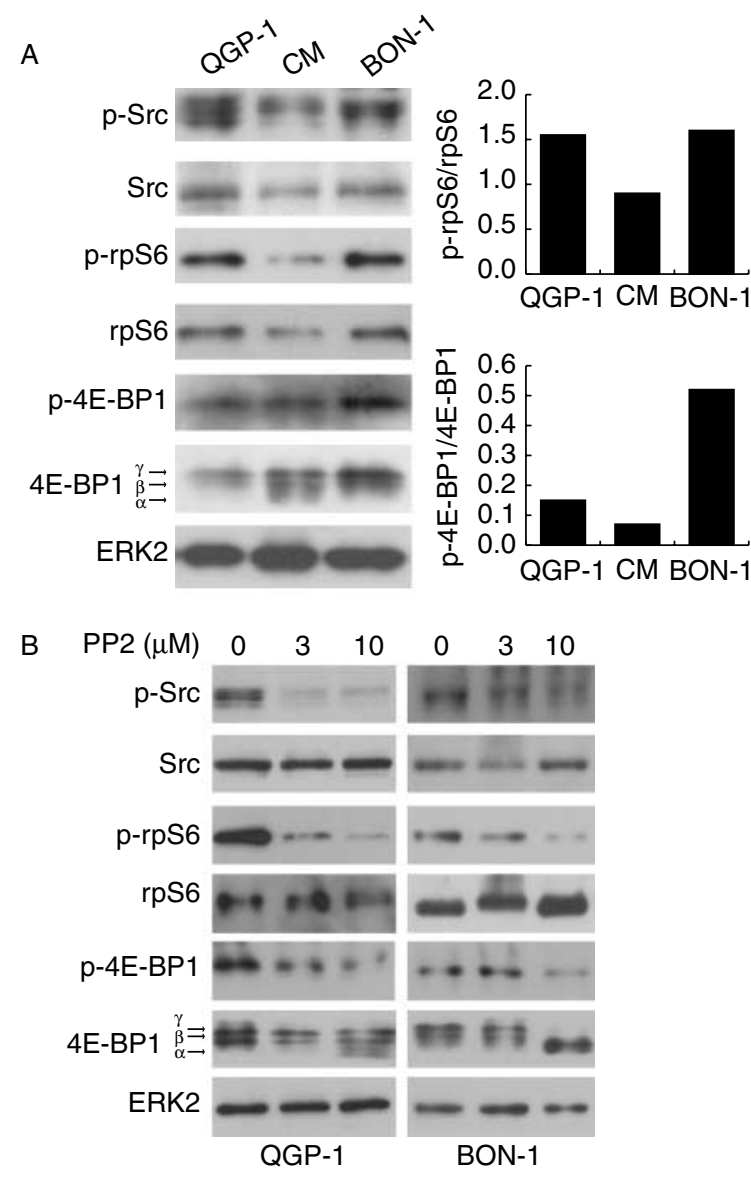

Figure 1 Correlation between SFK and mTOR activities in PET cell lines. (A) Western blot analyses of the phosphorylation and activation status of Src, rpS6, and 4E-BP1 in QGP-1, BON-1, and $\mathrm{CM}$ cells. Densitometric analysis of the intensity of the bands in the western blots was performed by ImageQuant 5.1. Data represent ratio between the phosphorylated bands versus the total corresponding protein. (B) QGP-1 and BON-1 cells were treated for $4 \mathrm{~h}$ with or without the indicated doses of PP2. Cell extracts were analysed in western blot for the indicated proteins.

These results suggested a possible correlation between SFK and mTOR activities in PET cell lines. To test this hypothesis, QGP-1 and BON-1 cells were treated for $4 \mathrm{~h}$ with two doses $(3$ and $10 \mu \mathrm{M})$ of the SFK inhibitor PP2. As shown in Fig. 1B, inhibition of SFK activity caused a decrease in phosphorylation of both 4E-BP1 and rpS6, further indicating a role for SFKs upstream of mTOR in these PET cell lines.

\section{SFKs trigger activation of the mTOR pathway during PET cell adhesion}

Src is activated during PET cell adhesion and spreading on the extracellular matrix (Di Florio et al. 2007). Since activation of mTOR-dependent protein synthesis occurs during adhesion of some cell types
(Gorrini et al. 2005), we asked whether mTOR was activated in a Src-dependent manner during QGP-1 cell adhesion. Phosphorylation of rpS6 and 4E-BP1, monitored by the levels of the slower migrating forms ( $\beta$ and $\gamma$ in Fig. 2A), was elevated during adhesion. Densitometric analysis of rpS6 phosphorylation pointed out that mTOR was maximally activated after $30 \mathrm{~min}$ (Fig. 2B). By contrast, when cells were treated with the SFK inhibitor PP2, phosphorylation of both rpS6 and 4E-BP1 was almost completely suppressed throughout the time course of the experiment (Fig. 2A and B). Treatment of QGP-1 cells in suspension with PP2 reduced the basal phosphorylation of extracellular regulated kinases (ERKs) and AKT, which may account for the lower levels of phosphorylation of mTOR targets observed before adhesion (Fig. 2A). Nevertheless, phosphorylation of ERKs and AKT upon adhesion was delayed but not abolished by inhibition of SFK activity, suggesting a more direct effect of SFK on mTOR during adhesion. Inhibition of the mTOR pathway by PP2 treatment directly correlated with inhibition of cell adhesion and spreading, as visualised by staining of the actin cytoskeleton (Fig. 2C) and by cell count (Supplementary figure $1 \mathrm{~A}$, see section on supplementary data given at the end of this article). The effect of PP2 on phosphorylation of mTOR targets was dose-dependent (Supplementary figure 1B, see section on supplementary data given at the end of this article) and specific, because its inactive analogue PP3 was ineffective (Fig. 2A-C and Supplementary figure 1A, see section on supplementary data given at the end of this article). Moreover, mTOR inhibition could be achieved using the unrelated SFK inhibitor Src kinase inhibitor I (Bain et al. 2007; Supplementary figure 1A and $\mathrm{C}$, see section on supplementary data given at the end of this article). SFK inhibition suppressed activation of the mTOR pathway also during QGP-1 cell adhesion on fibronectin (Supplementary figure 2A and $\mathrm{C}$, see section on supplementary data given at the end of this article) or in the carcinoid cell line BON-1 (Supplementary figure 1D, see section on supplementary data given at the end of this article). Src was likely responsible for this effect, because inhibition of the mTOR pathway during QGP-1 cell adhesion could be achieved by RNAi depletion of endogenous Src (Fig. 2D and E).

Depletion of Src or its pharmacological inhibition also impaired PET cell adhesion (Fig. 3A and Supplementary figure 1A, see section on supplementary data given at the end of this article; Di Florio et al. 2007). To rule out the possibility that mTOR is activated during adhesion independently of Src, we 
A

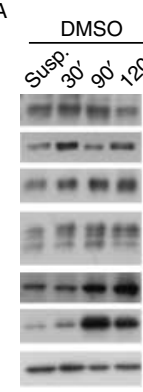

C

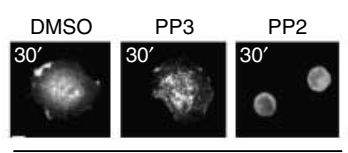

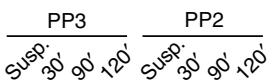
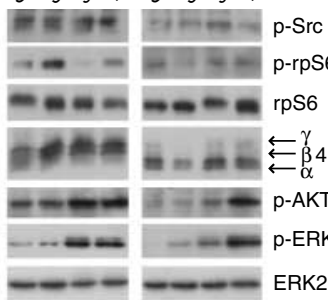

p-rps6

$=-\mathbf{m} \operatorname{rpS} 6$

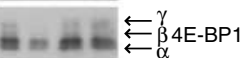

$=-\mathrm{p}-\mathrm{AKT}$

p-ERK
B

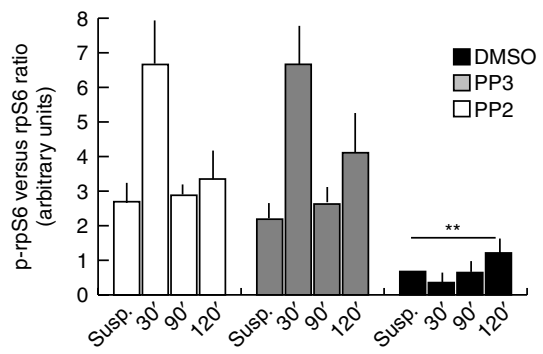

D

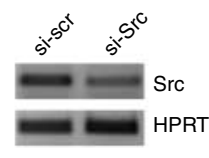

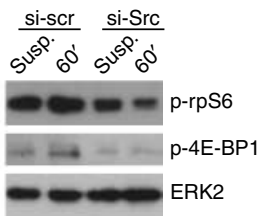

Figure 2 SFK activity regulates the activation of mTOR pathway during adhesion of QGP-1 cells. (A) Western blot analysis of the phosphorylation of rpS6 and 4E-BP1 in QGP-1 allowed to adhere on FBS-precoated plates for 30, 90, and $120 \mathrm{~min}, \pm 10 \mu \mathrm{M}$ PP2 inhibitor or its inactive analogue PP3. (B) Densitometric analysis of rpS6 phosphorylation (p-rpS6) expressed as ratio of band intensities versus the total rpS6 band (mean \pm s.D. of three experiments). Statistical analysis was performed by ANOVA test with Dunnett's multiple comparison test versus control (DMSO; ${ }^{* \star} P<0.001$ ). (C) TRITC-labelled phalloidin staining of QGP-1 cells during adhesion (30 $\mathrm{min}$ ) in the presence of the indicated drugs. (D) RT-PCR analysis of Src and HPRT in QGP-1 cells transfected with si-scrambled (si-scr) or si-Src siRNAs. (E) Western blot analysis of rpS6 and 4E-BP1 phosphorylation status of QGP-1 silenced with si-scr or si-Src during adhesion on FBS-precoated plates (60 min).

performed adhesion assays on poly-L-lysine (PLL)coated plates, where cells attach by electrostatic interactions. mTOR was activated at 90 and $120 \mathrm{~min}$ after the onset of adhesion on PLL. Notably, inhibition of SFKs suppressed mTOR activation (Supplementary figure $2 \mathrm{~B}$, see section on supplementary data given at the end of this article) without interfering with QGP-1 cells adhesion (Supplementary figure 2D, see section on supplementary data given at the end of this article; Di Florio et al. 2007). These results strongly suggest that Src functions upstream of mTOR in PET cells.

\section{Src locally activates the mTOR pathway at the cell periphery during adhesion}

Src is enriched in the plasma membrane near sites of actin cytoskeleton turnover during cell spreading (arrows in Fig. 3A). A fraction of the translation factors regulated by mTOR is also localised at the cell periphery, in close proximity to microtubules and focal adhesion sites (Willett et al. 2006). Thus, we asked whether Src activity played a role in localised activation of the mTOR pathway. Phosphorylation of rpS6 was strongly enriched in the membrane protrusions at the cell periphery in adhering QGP-1 cells (Fig. 3B). Most cells treated with PP2 did not spread even after prolonged attachment to the substrate (Fig. 2C). Nevertheless, in cells that spread after $1 \mathrm{~h}$ in the presence of PP2, the peripheral enrichment of
p-rpS6 was abolished, whereas staining in the cell body was largely maintained (Fig. 3B). By contrast, treatment with rapamycin completely abolished p-rpS6 throughout the cell (Fig. 3B). Phosphorylation of p-rpS6 in the membrane protrusions was likely due to activation of Src, as it was similarly inhibited by RNAi depletion of the endogenous protein (Fig. 3C, Supplementary figure $3 \mathrm{~A}$, see section on supplementary data given at the end of this article). These results suggested that $\mathrm{Src}$ activity locally sustains activation of the mTOR pathway at the cell periphery.

To interfere with Src activity by a different means, QGP-1 cells were transfected with a construct encoding GFP-SrcKD. This mutant displayed dominant-negative activity and inhibited cell adhesion, whereas GFP-SrcWT promoted it (Supplementary figure 3B, see section on supplementary data given at the end of this article). Moreover, GFP-SrcKD overexpression reduced rpS6 and 4E-BP1 phosphorylation, in HEK293T cells (Supplementary figure 3C, see section on supplementary data given at the end of this article). We observed that p-rpS6 was enriched in plasma membrane districts where GFP-SrcWT was also accumulated in adhering QGP-1 cells (Fig. 3D). By contrast, in cells overexpressing GFP-SrcKD, localisation of p-rpS6 in these peripheral sites was lost, whereas staining in the rest of the cell body was not sensibly affected. Similar results were also 
observed with phosphorylation of 4E-BP1 (Supplementary figure $3 \mathrm{D}$, see section on supplementary data given at the end of this article), confirming that activation of Src stimulates the mTOR pathway at peripheral sites of actin cytoskeleton turnover.

A

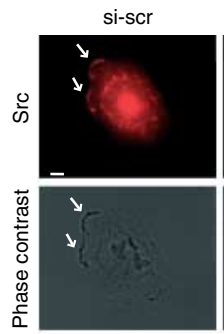

B

p-rpS6

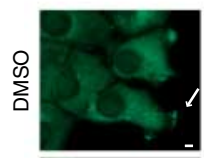

Phalloidin

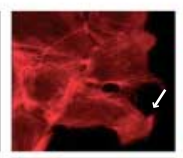

Merge
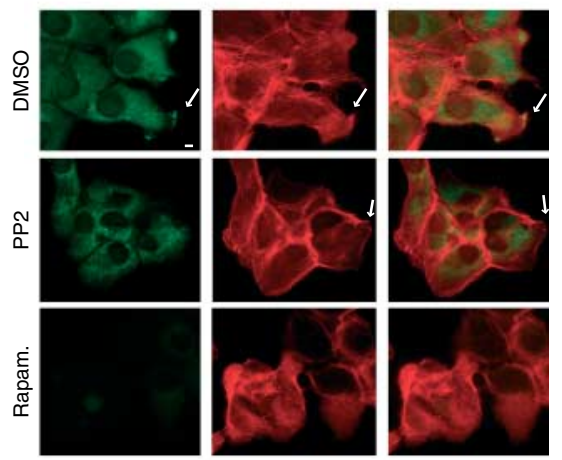

C

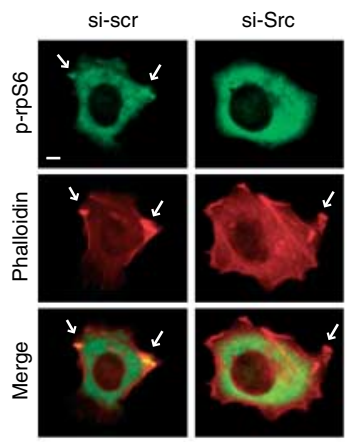

D

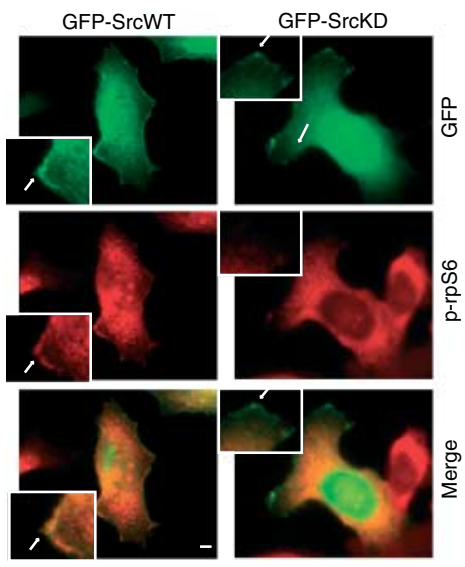

\section{SFK activity regulates protein synthesis during PET cell adhesion}

The oncogenic role of mTOR is mainly attributed to regulation of cap-dependent mRNA translation (Averous \& Proud 2006). Thus, we investigated whether SFK activity modulates mRNA translation and protein synthesis. Treatment of QGP-1 and BON-1 cells undergoing adhesion with PP2 strongly decreased the rate of protein synthesis, as determined by ${ }^{35} \mathrm{~S}$ methionine incorporation (Fig. 4A and Supplementary figure 4A, see section on supplementary data given at the end of this article). This result was confirmed also by a different approach. QGP-1 cell extracts were fractionated on sucrose gradients to separate the translationally active polyribosomes (polysomes) from the monosome (80S) and the ribonucleoprotein (RNP) fractions (Fig. 4B). Cells treated with PP2 showed a strong reduction in the polysome peaks and a corresponding increase in the monosome fraction at both 60 and $120 \mathrm{~min}$, confirming the reduced mRNA translation rate. These results indicated that SFK activity modulates protein synthesis in QGP-1 cells.

mTOR regulates translation through assembly of the eIF4F complex on the $5^{\prime}$-terminal $\mathrm{m}^{7} \mathrm{G}$ cap of the mRNA (Richter \& Sonenberg 2005). eIF4F comprises the cap-binding protein eIF4E, the scaffold protein eIF4G and the eIF4A helicase. Phosphorylation of the inhibitory eIF4E-binding protein 4E-BP1 by mTOR causes its dissociation from eIF4E and promotes recruitment of eIF4G (Richter \& Sonenberg 2005). Pull-down assays with $\mathrm{m}^{7} \mathrm{GTP}$-sepharose beads, which mimic the mRNA $5^{\prime}$-cap, showed that eIF4E associated with eIF4G to form an active eIF4F complex in control QGP-1 cells undergoing adhesion. However, when SFK activity was inhibited by PP2, eIF4E was

Figure 3 Interfering with SFK activity suppresses activation of the mTOR pathway at the cell periphery. (A) QGP-1 cells were transfected with si-Src or si-scr siRNAs and $48 \mathrm{~h}$ later were allowed to adhere on FBS-precoated plated for $30 \mathrm{~min}$ and immunostained for Src. Specificity was demonstrated by the reduced signal in cells silenced for Src, which remained rounded upon adhesion (phase contrast images in lower panels). (B) Immunofluorescence analysis for p-rpS6 and phalloidin of QGP-1 cells treated for 60 min with $10 \mu \mathrm{M}, \mathrm{PP} 2$ or $50 \mathrm{nM}$, rapamycin. White arrows show sites where p-rpS6 staining is enriched at the cell periphery. (C) Immunofluorescence analysis for p-rpS6 and phalloidin of QGP-1 cells depleted of endogenous Src, during adhesion on FBS-precoated plates $(30 \mathrm{~min})$. White arrows show sites where p-rpS6 staining is enriched at the periphery of the cell. (D) Adhering QGP-1 cells (60 min) transfected with wild type (WT) or kinasedead (KD) GFP-Src were stained for p-rpS6 by immunofluorescence. White arrows in the insets indicate sites where Src is enriched at the cell periphery. No enrichment of p-rpS6 staining was observed in the presence of GFP-SrcKD; bars $=5 \mu \mathrm{m}$. 
A

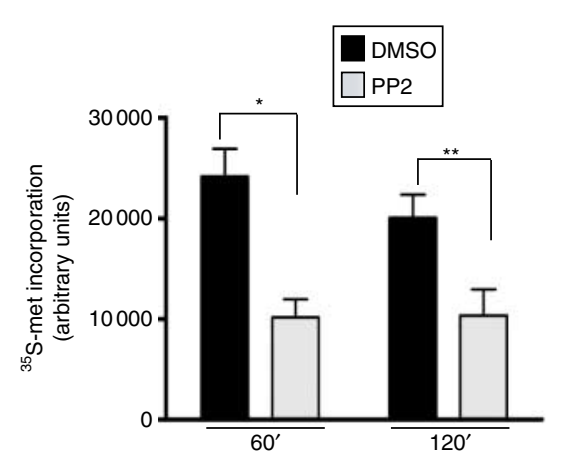

B

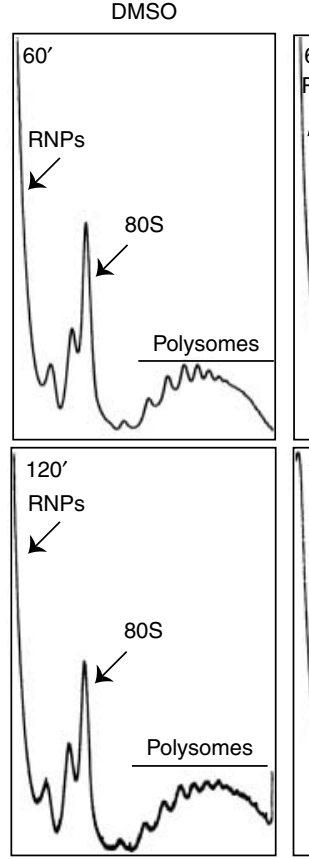

C
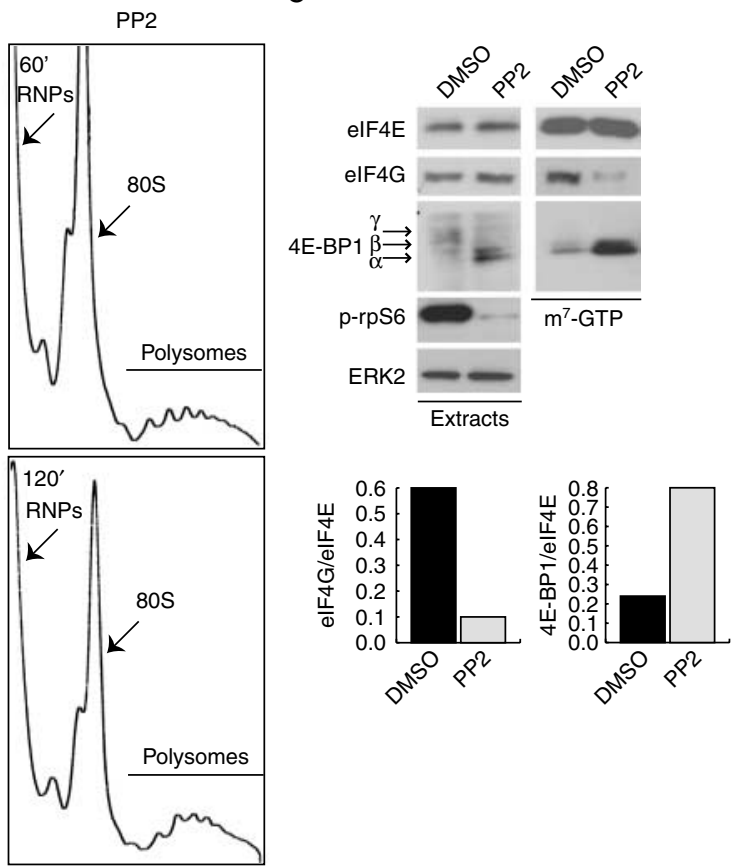

Figure 4 SFK activity regulates protein synthesis and assembly of elF4F during PET cell adhesion. (A) QGP-1 cells treated with DMSO or $10 \mu \mathrm{M}$ PP2 in the presence of ${ }^{35} \mathrm{~S}$-methionine were seeded on FBS-precoated plates for 60 and $120 \mathrm{~min}$. Cells were then processed to evaluate protein synthesis levels by measuring ${ }^{35} \mathrm{~S}$-methionine incorporation (CPM/ $\mathrm{\mu g}$ of proteins; mean \pm S.E.M. of three experiments. Two-tailed $t$-test, versus control ${ }^{* *} P<0.01$ and ${ }^{*} P<0.05$. (B) Absorption profiles $\left(A_{254}\right)$ from sucrose gradient fractionation of adhering QGP-1 cells treated with PP2 $10 \mu \mathrm{M}$. Polysomes, RNP-containing fractions and ribosomal subunits and monosome peaks are indicated. (C) $\mathrm{m}^{7}$-GTP-sepharose pull-down assay of extracts from adhering QGP-1 cells (120 min). Western blot analysis of elF4E, elF4G, and 4E-BP1 as indicated. Cell extracts were also analysed p-rpS6 and ERK2 staining was used as loading control. Densitometric analysis of the amount of elF4G or 4E-BP1 proteins bound to elF4E in $\mathrm{m}^{7}$-GTP-sepharose pull-down assay is shown in lower panels.

preferentially associated with the inhibitory protein 4E-BP1, with only residual binding to eIF4G (Fig. 4C). This result shows that regulation of the mTOR pathway by SFK controls formation of the eIF4F complex and might affect mRNA translation.

\section{SFK activity controls translation of a subset of mRNAs during QGP-1 cell adhesion}

To investigate whether translation of specific mRNAs is modulated by SFKs, we isolated mRNAs from the polysome fractions of adhering QGP-1 cells (see absorbance profiles in Fig. 4B). Purified mRNAs were hybridised with microarray membranes containing 440 genes that are frequently deregulated in cancer. We identified 49 mRNAs whose translation is sensitive to SFK activity (Fig. 5A and Supplementary figure 4B, see section on supplementary data given at the end of this article). Among these transcripts, there was an enrichment in mRNAs encoding cell cycle proteins (Fig. 5B and Supplementary figure $4 \mathrm{C}$, see section on supplementary data given at the end of this article). Microarray data were validated by PCR analysis for cyclin D1, cyclin E1, polo-like kinase 2 (Plk2/SNK) and the cyclin-dependent kinase inhibitor p21 (Fig. 5C). To rule out an effect of PP2 on transcription or RNA stability, we compared the levels of these mRNAs in the polysome fractions with those in total RNA obtained from the same cells. For all four transcripts, we observed a specific reduction in the polysome fractions with none or minimal reduction in total RNA levels (Fig. 5C and D). Thus, SFK activity specifically modulates translation of these mRNAs during QGP-1 cell adhesion. Furthermore, PP2 treatment caused a decrease in cyclin D1, cyclin E1 and p21 protein levels (Fig. 5E), indicating that translational regulation was sufficient to affect protein concentration in PET cells. Lastly, rapamycin caused a similar decrease in cyclin D1, cyclin E1 and p21 protein levels (Fig. 5E), further supporting a function for mTOR in SFK-regulated mRNA translation. These results suggest a novel role for SFKs in regulating the synthesis of cell cycle proteins through activation of mTOR. 


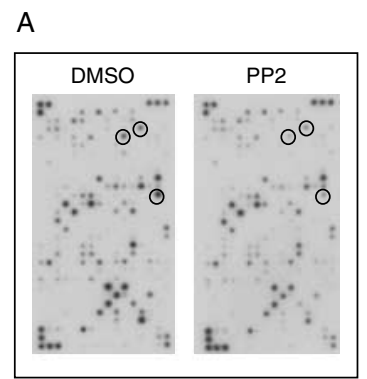

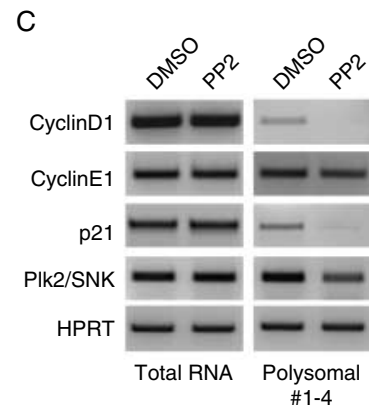
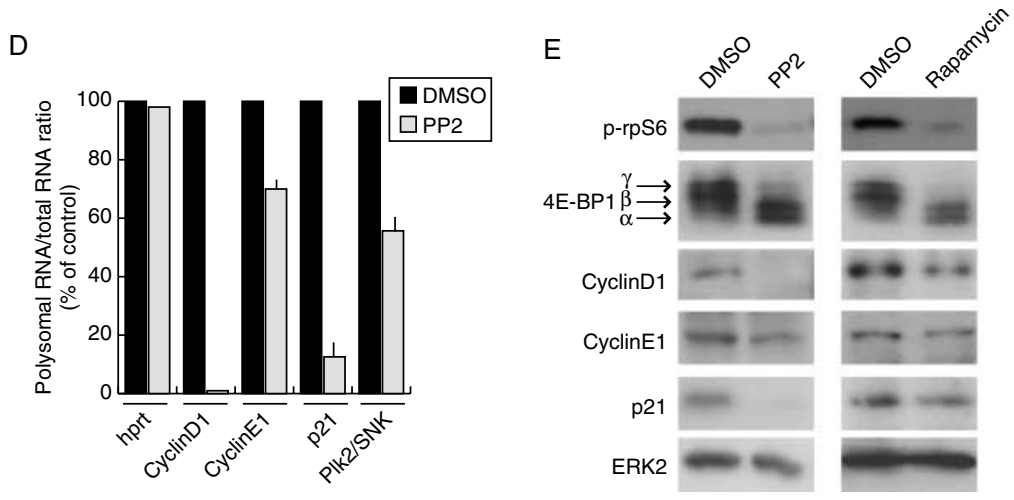

Figure 5 SFK activity regulates translation of a subset of mRNAs in PET cells. (A) Representative images of Superarray cancer chips; circles represent examples of mRNAs down-regulated on polysomes in PP2-treated adhering QGP-1 cells. (B) Table of genes involved in cell cycle regulation, whose translation depends on SFK activity. (C) Selected mRNAs were validated by RT-PCR analysis of total and polysomal fractions. (D) Ratio of mRNA levels of polysomes versus total mRNA analysed in (C). (E) Western blot analysis of extracts from adhering QGP-1 cells \pm PP2 or rapamycin of proteins encoded by mRNAs analysed in (C).

\section{SFK inhibition represses mTOR activity without activation of the AKT survival pathway}

Since SFKs modulate mTOR-dependent synthesis of cell cycle-related proteins in QGP-1 cells, we tested whether concomitant inhibition of SFK and mTOR pathways reduced PET cell proliferation. When QGP-1 cells were treated with PP2 and RAD001, a clinically tested mTOR inhibitor, cell growth was only modestly inhibited by either drug alone (Fig. 6A). However, when the inhibitors were supplied together, they synergistically reduced cell proliferation (Fig. 6A). A similar effect was also observed in BON-1 cells, which were more sensitive to both PP2 and RAD001 compared with QGP-1 cells (Supplementary figure $5 \mathrm{~A}$, see section on supplementary data given at the end of this article). These results suggest a cooperation between the SFK and mTOR pathways in PET cell proliferation.

The application of mTOR inhibitors to suppress cancer cell growth is limited by the feedback activation of escape mechanisms through phosphorylation of the PI3K/AKT survival pathway (Wan et al. 2007).
Since AKT can be activated independently by mTOR and SFKs (Lu et al. 2003, Huang \& Manning 2009), we asked whether inhibition of SFK activity could block mTOR and prevent activation of the AKT pathway at the same time. First, QGP-1 and BON-1 cells were starved by serum depletion and then stimulated by addition of FBS for $30 \mathrm{~min}$. Under these conditions, serum caused activation of mTOR, as indicated by the increase in rpS6 phosphorylation and in the slower migrating forms of 4E-BP1 (Fig. 6B and Supplementary figure $5 \mathrm{~B}$, see section on supplementary data given at the end of this article). Phosphorylation of Src was also increased by FBS, and RAD001 further augmented both phosphorylation of Src and AKT, indicating activation of growth pathways after inhibition of mTOR in PET cells. Treatment with PP2 partially repressed rpS6 phosphorylation in QGP-1 cells, compared with full inhibition by RAD001 (Fig. 6B), indicating that SFKs participate to activation of the mTOR pathway in the short-term response to serum. We also found that, unlike RAD001, PP2 repressed phosphorylation of AKT induced by FBS in both PET cell lines. Importantly, concomitant 
A

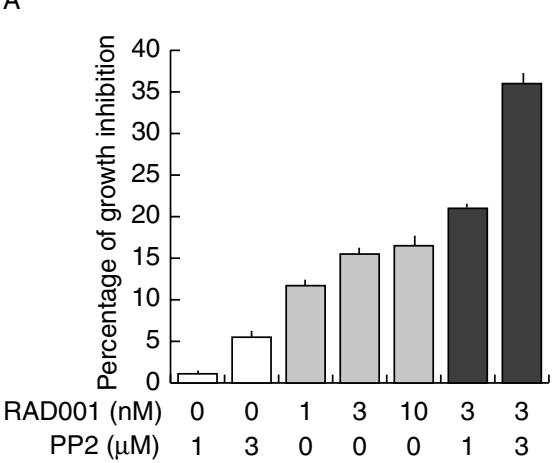

C

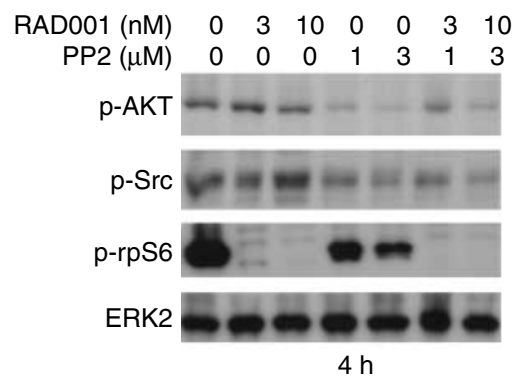

RAD001 (nM) $0 \begin{array}{llllllll} & 3 & 10 & 0 & 0 & 3 & 10\end{array}$

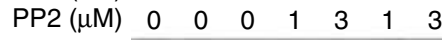

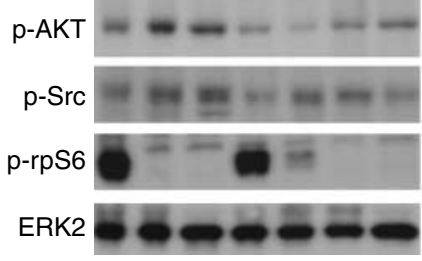

$24 \mathrm{~h}$
B

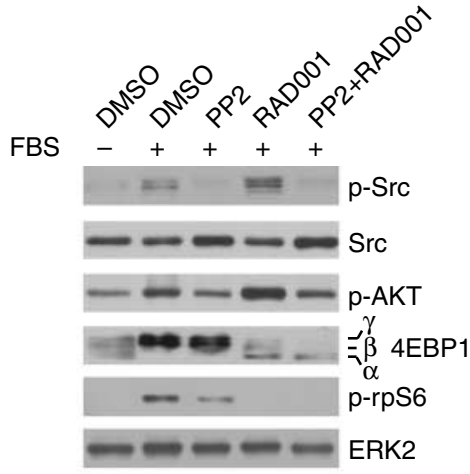

D
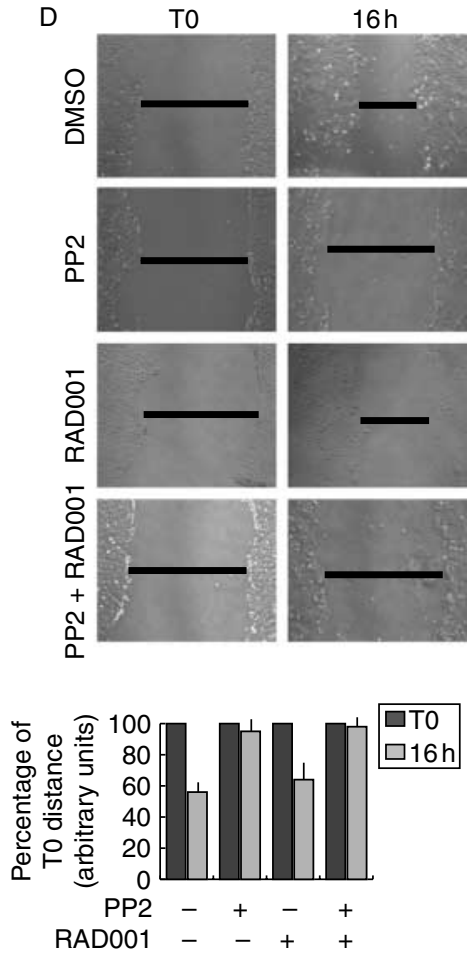

Figure 6 SFK inhibition blocks activation of the mTOR pathway without triggering activation of AKT in PET cells. (A) QGP-1 cell proliferation was measured by the CellTiter 96 Kit after treatment with the indicated concentration of PP2 and RAD001 for $72 \mathrm{~h}$ (mean \pm s.D. of three experiments). (B) Western blot analysis of AKT, rpS6 and 4E-BP1 phosphorylation in QGP-1 stimulated with FBS (30 min), \pm DMSO, $10 \mu \mathrm{M}$ PP2 or $10 \mathrm{nM}$ RAD001. (C) Western blot analysis as in (B) of extracts obtained from QGP-1 cells treated for 4 and $24 \mathrm{~h}$ with DMSO or the indicated doses of PP2 and RAD001, either alone or in combination. (D) Scar migration assay of QGP-1 cells treated with $10 \mu \mathrm{M}$ PP2 and $10 \mathrm{nM}$ RAD001 for $16 \mathrm{~h}$. The extent of cell migration is shown in the bottom graph as a percentage of the reduction of the scar length compared with the initial scar length (T0 distance).

treatment with the two inhibitors completely suppressed activation of the mTOR pathway without causing activation of AKT with respect to control QGP-1 and BON-1 cells (Fig. 6B and Supplementary figure $5 \mathrm{~B}$, see section on supplementary data given at the end of this article).

Long-term inhibition of mTOR ( 4 or $24 \mathrm{~h}$ ) also triggered phosphorylation and activation of AKT in QGP-1 cells (Fig. 6C), as previously reported in other cell types and in vivo during clinical trials (Phung et al. 2007, Meric-Bernstam \& Gonzalez-Angulo 2009). As observed for the short-term stimulation (Fig. 6B), treatment with RAD001 increased phosphorylation of Src (Fig. 6C). Moreover, long-term treatment of QGP-1 cells with PP2 concomitantly repressed the mTOR pathway and AKT phosphorylation (Fig. 6C). This result suggested that SFK-dependent activation of AKT during mTOR inhibition underlies the synergistic 
effect PP2 and RAD001 on QGP-1 proliferation (Fig. 6A). To directly test this hypothesis, we examined activation of AKT in cells treated with PP2 and RAD001 in combination. Remarkably, co-treatment of QGP-1 cells with RAD001 and PP2 led to complete inhibition of mTOR while preventing activation of the AKT pathway (Fig. 6C). Importantly, inhibition of Src activity by PP2 also completely suppressed the ability of QGP-1 cells to migrate and colonise a scar in the dish, whereas RAD001 only exerted a small effect on cell migration (Fig. 6D). These results suggest that concomitant inhibition of the mTOR and SFK pathways might strongly impair PET cell proliferation by suppressing protein synthesis while preventing activation of the PI3K/AKT pathway.

\section{Expression of p-Src and 4E-BP1 in PET samples}

Our previous study indicated that $\mathrm{Src}$ is up-regulated in PET samples compared with normal islet cells (Di Florio et al. 2007). Activation of some components of the mTOR pathway was also observed in PETs (Missiaglia et al. 2010), and mutations in the genes of this pathway have been recently found in PET patients (Jiao et al. 2011). To test whether Src and mTOR were activated in PET patients, we performed western blot and IHC. Analysis of proteins extracted from six primary PET lesions indicated that Src phosphorylation was increased in all patients, with respect to normal pancreatic tissue and adenocarcinoma cells (Fig. 7A). The mTOR activity was also increased in four of these patients, as indicated by phosphorylation of 4E-BP1, whereas no detectable phosphorylation was observed in the remaining two samples (Fig. 7A).

To extend these observations to a larger number of patients, we performed IHC analysis of a PET TMA containing specimens from 31 patients, whose clinical and pathological data had been recorded. Staining for total 4E-BP1 was positive in $30 / 31$ analysed cases (cores for one patient were considered not reliable; Fig. 7B and C). Twenty-six cases (83\%) showed diffuse staining of most cells (group B, see Materials and methods), whereas four cases (13\%) showed a small percentage of positive cells (group A). In most cases staining was mainly cytoplasmic, although nuclear staining was also visible. Intensity of total 4E-BP1 staining was not associated with any clinical or pathological data. Staining for the p-4E-BP1 was positive in $12 / 31(38.7 \%)$ cases analysed (Fig. 7B and C), with ten samples belonging to the group A. Staining was both nuclear and cytoplasmic in $8 / 12$ cases, only nuclear in $2 / 12$ and only cytoplasmic in $2 / 12$. A worse prognosis was observed in patients

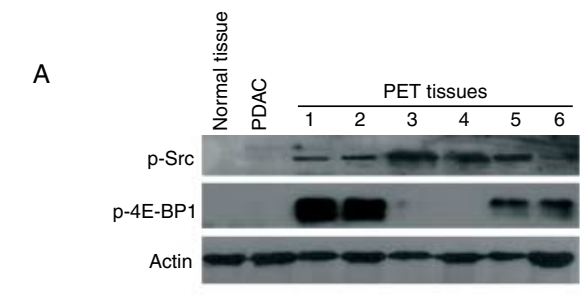

B

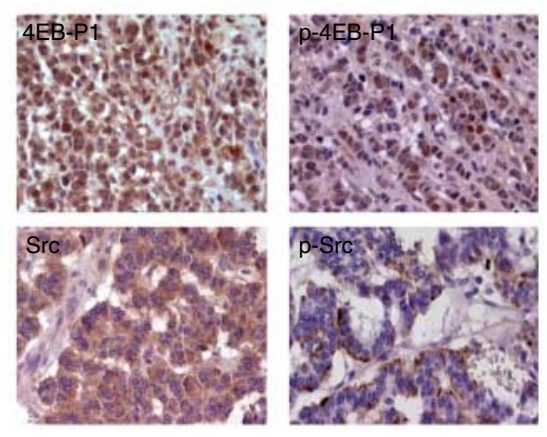

C
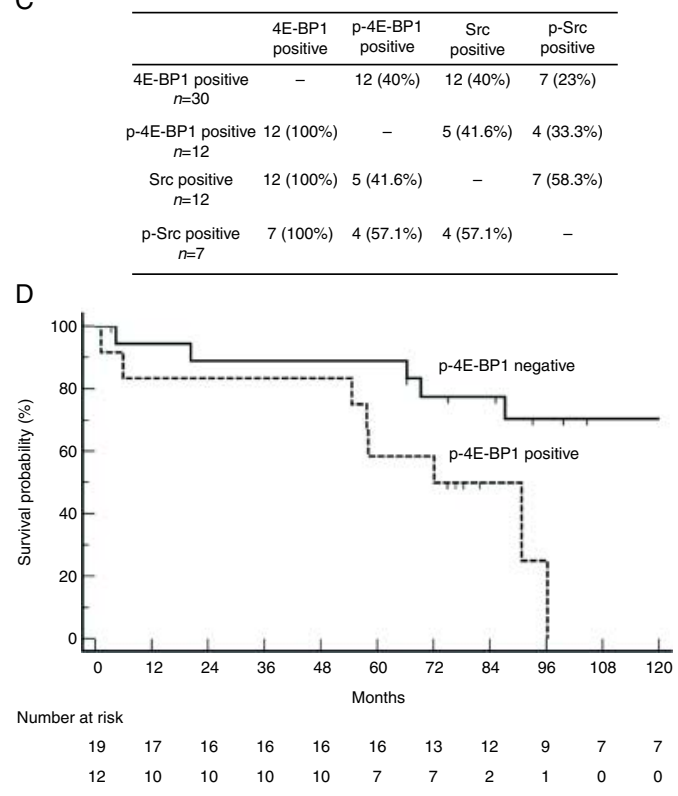

Figure 7 Expression and phosphorylation of Src and 4E-BP1 proteins in PET samples. (A) Western blot analysis of the phosphorylation and activation status of Src and 4E-BP1 in normal pancreatic tissue (lane 1), the pancreatic adenocarcinoma cell line PSN1 (PDAC, lane 2) and in six PET samples (PET tissues, lanes $3-8$ ). (B) Images (40× objective) showing representative IHC analyses of PET tissue arrays. In clockwise order, the panels show: strong and diffuse cytoplasmic and nuclear staining for total 4E-BP1, strong nuclear staining for phosphorylated 4E-BP1 ( $p-4 E-B P 1)$ in most cells of the same sample, strong cytoplasmic staining for phosphorylated Src $(\mathrm{p}-\mathrm{Src})$ in the same sample and diffuse cytoplasmic staining for total Src, as indicated. (C) The table highlights the correlation between the different IHC staining. Out of 31 PET cases evaluated, the number of samples positive for each antibody is listed in the first column on the left in bold. Each line shows the number (and percentage) of positivity for each other antibody. (D) Survival likelihood according with expression of phosphorylated 4E-BP1 ( $\mathrm{p}-4 \mathrm{E}-\mathrm{BP} 1) ; P=0.014$ at log-rank test. 
with p-4E-BP1 staining (log-rank test $P=0.014$; Fig. 7D). Staining for $\mathrm{p}-4 \mathrm{E}-\mathrm{BP} 1$ was associated with worse survival of patients in a Cox proportionalhazards regression model too. Univariate (hazard ratio (HR) 3.8; 95\% confidence interval (CI) 1.2-12.3; $P=0.04$ ) and multivariate (HR 6.5; 95\% CI 1.6-26.3; $P<0.0001)$ analyses showed statistical significance, suggesting that phosphorylation of $4 \mathrm{E}-\mathrm{BP} 1$ is an independent marker of poor prognosis in PETs. Other factors significantly associated with poor survival were primary tumour size (HR 1.01; 95\% CI 1-1.03 per each $\mathrm{mm}, P=0.03$ ), a Ki67 index $>5 \%$ (HR $3.1 ; 95 \% \mathrm{CI}$ $1-9.4 ; P=0.04)$ and metastatic disease at diagnosis (HR 9.7; 95\% CI 3.1-30.2; $P=0.0002$ ).

Staining for total Src was positive in 12/31 (38.7\%) cases (Fig. 7B and C), five were included in group A and seven in group $\mathrm{B}$, without correlation with clinical and/or pathological data. Staining for $\mathrm{p}$-Src was positive in 7/32 (21.8\%) cases (Fig. 7B and C), six were included in group $\mathrm{A}$ and one in group $\mathrm{B}$. As expected, immunostaining was detected only in the cytoplasm or at the plasma membrane. Of the seven patients positive for $\mathrm{p}$-Src, four (57\%) were also positive for $\mathrm{p}-4 \mathrm{E}-\mathrm{BP} 1$, while only $28 \%$ of those negative for $\mathrm{p}-\mathrm{Src}$ were positive for $\mathrm{p}-4 \mathrm{E}-\mathrm{BP} 1$. Nevertheless, this difference was not statistically significant, possibly due to the relatively low sample size, nor a significant correlation between the two IHC staining was found. Staining for $\mathrm{p}$-Src was not associated with clinical data nor with survival of the patients.

\section{Discussion}

In this study, we have identified a new role for SFKs in the regulation of the mTOR pathway and mRNA translation in PET cells. Our results clearly show that activation of SFKs during cell adhesion, an Src-dependent process with strong relevance for cancer cell invasiveness, stimulates the mTOR pathway and leads to increased protein synthesis in PET cells. Notably, inhibition of SFK activity blocked the mTOR pathway without triggering activation of survival pathways stimulated by mTOR inhibitors in cancer cells. Moreover, concomitant treatment with SFK and mTOR inhibitors synergistically reduced PET cell proliferation.

Profound changes in cellular cytoskeleton occur during cell adhesion, spreading and migration. These processes are often activated in cancer cells and promote invasion of neighbouring tissues and spreading of metastatic lesions. SFK activity is strictly required for these processes in PET cells (Di Florio et al. 2007). Our studies, using two unrelated SFK inhibitors (Bain et al. 2007), depletion of the endogenous Src, and up-regulation of a dominantnegative mutant of the kinase, now link SFK activity with regulation of the mTOR pathway during cell adhesion. Importantly, cell adhesion, together with changes in cell morphology, triggers activation of mRNA translation (Gorrini et al. 2005). This process is regulated at the initiation step by mTOR through phosphorylation of S6K and 4E-BP1 (Hay \& Sonenberg 2004). We found that SFK activity is required to direct activation of mTOR at the cell periphery, nearby sites of actin cytoskeleton turnover. Thus, our results support a model in which activation of SFKs during adhesion couples morphological changes in the cell with activation of mRNA translation. Few reports have suggested a role for SFKs in translational regulation. For example, Src regulates translation of the actin mRNA in lamellipodia of migrating cells through phosphorylation of the RNA-binding protein ZBP1 (Huttelmaier et al. 2005). However, this regulation did not involve the mTOR/ eIF4F pathway. A potential regulation of mTOR was instead proposed for the Src substrate focal adhesion kinase (FAK) (Thamilselvan et al. 2007), whose overexpression causes phosphorylation and inhibition of the mTOR negative regulator TSC2 (Gan et al. 2006). Our work now extends these studies and proposes a novel and more general contribution of SFKs in the regulation of the mTOR pathway and mRNA translation during adhesion. We focused our attention on Src because it is the most abundant and active SFK in QGP-1 cells (Di Florio et al. 2007). However, since SFKs share substrates and co-localise at the cell periphery (Frame et al. 2002), it is possible that other family members substitute $\mathrm{Src}$ in the regulation of the mTOR pathway during adhesion in other cancer cells.

Recent studies showed that mTOR activity modulates actin cytoskeleton remodelling and cell motility (Liu et al. 2010). This control is partially associated with post-transcriptional regulation of the expression of small GTPases (Liu et al. 2010). However, in our study inhibition of mTOR by RAD001 did not affect QGP-1 cell adhesion and exerted a very modest effect on their migration. On the other hand, our microarray results indicate that SFK activity is responsible for translational activation of a subset of mRNAs encoding for cell cycle proteins during cell adhesion. We suggest that adhesion activates a mitogenic programme that predisposes PET cells to proliferate. This regulation is exerted at the level of mRNA translation, presumably at sites of 
first contact with the matrix, through SFK-dependent activation of mTOR. Thus, adhering QGP-1 cells might be addressed towards replication by the same pathway that regulates their contact and attachment to the extracellular matrix. However, since SFKs also regulate intracellular secretory pathways and PET cells produce and secrete hormones and growth factors leading to autocrine cell proliferation, it is also possible that inhibition of SFKs contributes to repress autocrine signals that in turn modulate mTOR.

Activation of the mTOR pathway is a common feature in cancer (Averous \& Proud 2006, Meric-Bernstam \& Gonzalez-Angulo 2009), including PETs (Capurso et al. 2009, Missiaglia et al. 2010), providing support for therapeutic application of mTOR inhibitors. Encouraging data have been obtained in preclinical studies employing the mTOR inhibitor rapamycin on PET cell lines (Zitzmann et al. 2007). Clinical trials with the rapamycin analogues temsirolimus and everolimus (RAD001) in NETs also showed promising results (Capurso et al. 2009, Meric-Bernstam \& Gonzalez-Angulo 2009, Yao et al. 2009), with a response rate around $80 \%$ in patients with advanced, progressive PETs and previous failure of chemotherapy (Yao et al. 2009). Everolimus also elicited an increased progression-free survival in patients compared with placebo treatments (Yao et al. 2011). On the negative side, however, these compounds almost invariably lead to feedback survival responses that trigger activation of $\mathrm{PI} 3 \mathrm{~K}$ and $\mathrm{AKT}$ (Wan et al. 2007), thereby limiting their clinical application (Phung et al. 2007). This unwanted response has been observed in studies by PET models (Zitzmann et al. 2007) and other tumour types (Wan et al. 2007), as well as in clinical trials evaluating mTOR inhibitors (Phung et al. 2007). The activation of escape pathways in tumours cells exposed to targeted therapies have raised interest in the development of combined treatments. In this regard, the recent observation that SFK activity is responsible for the acquired resistance to trastuzumab and tamoxifen in breast cancer cells has opened a new path to control cancer progression (Zhang et al. 2011). Our work now shows that inhibition of mTOR by RAD001 results in activation of Src in PET cells, and that prevention of this effect by PP2 also blocks feedback activation of AKT by RAD001. In this scenario, our observation that SFK inhibitors synergise with RAD001 in suppressing PET cell proliferation might open new perspective for the use of mTOR inhibitors. Furthermore, inhibition of Src has profound effects on PET cell motility and adhesion (Di Florio et al. 2007), suggesting that targeting Src might also strongly impair the invasive potential of PET cells.

The analysis of human PET samples by western blot and IHC indicated that Src and the mTOR substrate 4E-BP1 are expressed and phosphorylated in some patients. In line with observations in other tumour types (Armengol et al. 2007), we found that phosphorylation of 4E-BP1 represents an independent factor associated with worse prognosis in PET patients. Notably, analysis of a large number of NET samples showed that expression and phosphorylation of 4E-BP1 is more frequent in foregut NETs, which include PETs, than in midgut NETs. Similarly to our results, phosphorylation of 4E-BP1 seems to identify more 'aggressive diseases', as it was correlated with a higher proliferation index (Jiao et al. 2011). We also tested the possibility that $\mathrm{Src}$ and mTOR activity correlated in PET specimens. Although most cases showing $\mathrm{p}$-Src immunoreactivity were also positive for p-4E-BP1, this correlation lacked statistical significance, possibly due to the relatively small number of evaluated samples. On the other hand, it is also possible that Src-dependent activation of the mTOR pathway occurs only in a subset of PET patients, as mutations in the mTOR pathway have been found in a quota of PET patients and might account for Src-independent phosphorylation of 4E-BP1. Larger studies with a higher number of patients will be required to establish a firm connection between phosphorylation of Src and 4E-BP1 in PET progression.

In conclusion, our results identify a new connection between the SFK and mTOR pathways in PET cells, which sustains protein synthesis and cell proliferation. Importantly, inhibition of SFK activity prevents the up-regulation of survival escape pathways by mTOR inhibitors in PET cells. These observations suggest that SFK inhibitors might be considered for future preclinical and clinical investigations in combination with mTOR inhibitors.

\section{Supplementary data}

This is linked to the online version of the paper at http://dx. doi.org/10.1530/ERC-10-0153.

\section{Declaration of interest}

The authors declare that there is no conflict of interest that could be perceived as prejudicing the impartiality of the research reported. 


\section{Funding}

This work was supported by Grants from The Associazione Italiana Ricerca sul Cancro (AIRC), the Association for International Cancer Research (AICR), the Istituto Superiore della Sanità (ISS Project n.527/B/3A/5), the Ministry of Education (PRIN 2006); The University of Rome La Sapienza (2009/C26F09NZLJ, 2009/C26A09N5NJ), It.A.NET (Italian Association for Neuroendocrine Tumours), Fondazione Cariverona, Verona, Italy.

\section{Acknowledgements}

We thank Prof. Fabrizio Loreni for protein synthesis measurements, Dr Federica Barbagallo for help with cell fluorescence analysis, Dr Daniela Barilà for generously providing pSGT-SrcWT and pSGT-SrcKD and Dr Giovanni Blandino for the gift of antibodies for p21 and Plk2/SNK.

\section{References}

Armengol G, Rojo F, Castellvi J, Iglesias C, Cuatrecasas M, Pons B, Baselga J \& Ramon y Cajal S 2007 4E-binding protein 1: a key molecular "funnel factor" in human cancer with clinical implications. Cancer Research 67 7551-7555. (doi:10.1158/0008-5472.CAN07-0881)

Averous J \& Proud CG 2006 When translation meets transformation: the mTOR story. Oncogene $\mathbf{2 5}$ 6423-6435. (doi:10.1038/sj.onc.1209887)

Bain J, Plater L, Elliott M, Shpiro N, Hastie CJ, McLauchlan H, Klevernic I, Arthur JS, Alessi DR \& Cohen P 2007 The selectivity of protein kinase inhibitors: a further update. Biochemical Journal 408 297-315. (doi:10.1042/ BJ20070797)

Bianchini A, Loiarro M, Bielli P, Busa R, Paronetto MP, Loreni F, Geremia R \& Sette C 2008 Phosphorylation of eIF4E by MNKs supports protein synthesis, cell cycle progression and proliferation in prostate cancer cells. Carcinogenesis 29 2279-2288. (doi:10.1093/carcin/ bgn221)

Bromann PA, Korkaya H \& Courtneidge SA 2004 The interplay between Src family kinases and receptor tyrosine kinases. Oncogene 23 7957-7968. (doi:10.1038/ sj.onc.1208079)

Capurso G, Lattimore S, Crnogorac-Jurcevic T, Panzuto F, Milione M, Bhakta V, Campanini N, Swift SM, Bordi C, Delle Fave G et al. 2006 Gene expression profiles of progressive pancreatic endocrine tumours and their liver metastases reveal potential novel markers and therapeutic targets. Endocrine-Related Cancer 13 541-558. (doi:10. 1677/erc.1.01153)

Capurso G, Fazio N, Festa S, Panzuto F, De Braud F \& Delle Fave G 2009 Molecular target therapy for gastroenteropancreatic endocrine tumours: biological rationale and clinical perspectives. Critical Reviews in Oncology/Hematology 72 110-124. (doi:10.1016/j.critrevonc.2009.01.008)
Di Florio A, Capurso G, Milione M, Panzuto F, Geremia R, Delle Fave G \& Sette C 2007 Src family kinase activity regulates adhesion, spreading and migration of pancreatic endocrine tumour cells. Endocrine-Related Cancer 14 111-124. (doi:10.1677/erc.1.01318)

Fitzgerald T, Hickner Z, Schmitz M \& Kort E 2008 Changing incidence of pancreatic neoplasms: a 16-year review of statewide tumor registry. Pancreas 37 134-138. (doi:10. 1097/MPA.0b013e318163a329)

Frame MC, Fincham VJ, Carragher NO \& Wyke JA 2002 v-Src's hold over actin and cell adhesions. Nature Reviews. Molecular Cell Biology 3 233-245. (doi:10. 1038/nrm779)

Gan B, Yoo Y \& Guan JL 2006 Association of focal adhesion kinase with tuberous sclerosis complex 2 in the regulation of s6 kinase activation and cell growth. Journal of Biological Chemistry 281 37321-37329. (doi:10.1074/ jbc.M605241200)

Gorrini C, Loreni F, Gandin V, Sala LA, Sonenberg N, Marchisio PC \& Biffo S 2005 Fibronectin controls cap-dependent translation through beta1 integrin and eukaryotic initiation factors 4 and 2 coordinated pathways. PNAS 102 9200-9205. (doi:10.1073/pnas. 0409513102)

Hay N \& Sonenberg N 2004 Upstream and downstream of mTOR. Genes and Development 18 1926-1945. (doi:10. 1101/gad.1212704)

Huang J \& Manning BD 2009 A complex interplay between Akt, TSC2 and the two mTOR complexes. Biochemical Society Transactions 37 217-222. (doi:10.1042/ BST0370217)

Huttelmaier S, Zenklusen D, Lederer M, Dictenberg J, Lorenz M, Meng X, Bassell GJ, Condeelis J \& Singer RH 2005 Spatial regulation of beta-actin translation by Srcdependent phosphorylation of ZBP1. Nature 438 512-515. (doi:10.1038/nature04115)

Jiao Y, Shi C, Edil BH, de Wilde RF, Klimstra DS, Maitra A, Schulick RD, Tang LH, Wolfgang CL, Choti MA et al. 2011 DAXX/ATRX, MEN1, and mTOR pathway genes are frequently altered in pancreatic neuroendocrine tumors. Science 331 1199-1203. (doi:10.1126/science. 1200609)

Koliopanos A, Avgerinos C, Paraskeva C, Touloumis Z, Kelgiorgi D \& Dervenis C 2008 Molecular aspects of carcinogenesis in pancreatic cancer. Hepatobiliary \& Pancreatic Diseases International 7 345-356.

Liu L, Luo Y, Chen L, Shen T, Xu B, Chen W, Zhou H, Han X \& Huang S 2010 Rapamycin inhibits cytoskeleton reorganization and cell motility by suppressing RhoA expression and activity. Journal of Biological Chemistry 285 38362-38373. (doi:10.1074/jbc.M110.141168)

Lu Y, Yu Q, Liu JH, Zhang J, Wang H, Koul D, McMurray JS, Fang X, Yung WK, Siminovitch KA et al. $2003 \mathrm{Src}$ family protein-tyrosine kinases alter the function of PTEN to regulate phosphatidylinositol 3-kinase/AKT cascades. Journal of Biological Chemistry 278 40057-40066. (doi:10.1074/jbc.M303621200) 
Mao W, Irby R, Coppola D, Fu L, Wloch M, Turner J, Yu H, Garcia R, Jove R \& Yeatman TJ 1997 Activation of c-Src by receptor tyrosine kinases in human colon cancer cells with high metastatic potential. Oncogene 15 3083-3090. (doi:10.1038/sj.onc.1201496)

Meric-Bernstam F \& Gonzalez-Angulo AM 2009 Targeting the mTOR signaling network for cancer therapy. Journal of Clinical Oncology 27 2278-2287. (doi:10. 1200/JCO.2008.20.0766)

Metz DC \& Jensen RT 2008 Gastrointestinal neuroendocrine tumors: pancreatic endocrine tumors. Gastroenterology 135 1469-1492. (doi:10.1053/j.gastro.2008.05.047)

Missiaglia E, Dalai I, Barbi S, Beghelli S, Falconi M, Della Peruta M, Piemonti L, Capurso G, iFlorio A, Delle Fave G et al. 2010 Pancreatic endocrine tumors: expression profiling evidences a role for AKT-mTOR pathway. Journal of Clinical Oncology 28 245-255. (doi:10.1200/ JCO.2008.21.5988)

Moore PS, Sipos B, Orlandini S, Sorio C, Real FX, Lemoine NR, Gress T, Bassi C, Kloppel G, Kalthoff H et al. 2001 Genetic profile of 22 pancreatic carcinoma cell lines. Analysis of K-ras, p53, p16 and DPC4/Smad4. Virchows Archiv : an International Journal of Pathology 439 798-802.

Panzuto F, Nasoni S, Falconi M, Corleto V, Capurso G, Cassetta S, Di Fonzo M, Tornatore V, Milione M, Angeletti S et al. 2005 Prognostic factors and survival in endocrine tumor patients: comparison between gastrointestinal and pancreatic localization. Endocrine-Related Cancer 12 1083-1092. (doi:10.1677/erc.1.01017)

Panzuto F, Di Fonzo M, Iannicelli E, Sciuto R, Maini C, Capurso G, Milione M, Cattaruzza M, Falconi M, David V et al. 2006 Long-term clinical outcome of somatostatin analogues for treatment of progressive, metastatic, well-differentiated entero-pancreatic endocrine carcinoma. Annals of Oncology 17 461-466. (doi:10.1093/annonc/mdj113)

Paronetto MP, Farini D, Sammarco I, Maturo G, Vespasiani G, Geremia R, Rossi P \& Sette C 2004 Expression of a truncated form of the c-kit tyrosine kinase receptor and activation of Src kinase in human prostatic cancer. American Journal of Pathology 164 1243-1251. (doi:10. 1016/S0002-9440(10)63212-9)

Paronetto MP, Zalfa F, Botti F, Geremia R, Bagni C \& Sette C 2006 The nuclear RNA-binding protein Sam68 translocates to the cytoplasm and associates with the polysomes in mouse spermatocytes. Molecular Biology of the Cell 17 14-24. (doi:10.1091/mbc.E05-06-0548)

Phung TL, Eyiah-Mensah G, O’Donnell RK, Bieniek R, Shechter S, Walsh K, Kuperwasser C \& Benjamin LE 2007 Endothelial Akt signaling is rate-limiting for rapamycin inhibition of mouse mammary tumor progression. Cancer Research 67 5070-5075. (doi:10.1158/ 0008-5472.CAN-06-3341)
Richter JD \& Sonenberg N 2005 Regulation of cap-dependent translation by eIF4E inhibitory proteins. Nature 433 477-480. (doi:10.1038/nature 03205)

Thamilselvan V, Craig DH \& Basson MD 2007 FAK association with multiple signal proteins mediates pressure-induced colon cancer cell adhesion via a Srcdependent PI3K/Akt pathway. FASEB Journal 21 1730-1741. (doi:10.1096/fj.06-6545com)

Wan X, Harkavy B, Shen N, Grohar P \& Helman LJ 2007 Rapamycin induces feedback activation of Akt signaling through an IGF-1R-dependent mechanism. Oncogene 26 1932-1940. (doi:10.1038/sj.onc.1209990)

Willett M, Flint SA, Morley SJ \& Pain VM 2006 Compartmentalisation and localisation of the translation initiation factor (eIF) $4 \mathrm{~F}$ complex in normally growing fibroblasts. Experimental Cell Research 312 2942-2953. (doi:10.1016/j.yexcr.2006.05.020)

Yao J, Eisner M, Leary C, Dagohoy C, Phan A, Rashid A, Hassan M \& Evans D 2007 Population-based study of islet cell carcinoma. Annals of Surgical Oncology 14 3492-3500. (doi:10.1245/s10434-007-9566-6)

Yao JC, Lombard-Bohas C, Baudin E, Kvols LK, Rougier P, Ruszniewski P, Hoosen S, St Peter J, Haas T, Lebwohl D et al. 2009 Daily oral everolimus activity in patients with metastatic pancreatic neuroendocrine tumors after failure of cytotoxic chemotherapy: a phase II trial. Journal of Clinical Oncology 28 69-76. (doi:10.1200/JCO.2009.24. 2669)

Yao JC, Shah MH, Ito T, Bohas CL, Wolin EM, Van Cutsem E, Hobday TJ, Okusaka T, Capdevila J, de Vries EG et al. 2011 Everolimus for advanced pancreatic neuroendocrine tumors. New England Journal of Medicine 364 514-523. (doi:10.1056/NEJMoa1009290)

Zhang S, Huang WC, Li P, Guo H, Poh SB, Brady SW, Xiong Y, Tseng LM, Li SH, Ding Z et al. 2011 Combating trastuzumab resistance by targeting SRC, a common node downstream of multiple resistance pathways. Nature Medicine 17 461-469. (doi:10.1038/ nm.2309)

Zitzmann K, De Toni EN, Brand S, Goke B, Meinecke J, Spottl G, Meyer HH \& Auernhammer CJ 2007 The novel mTOR inhibitor RAD001 (everolimus) induces antiproliferative effects in human pancreatic neuroendocrine tumor cells. Neuroendocrinology 85 54-60. (doi:10.1159/ 000100057)

Received in final form 1 June 2011 Accepted 27 June 2011 Made available online as an Accepted Preprint 28 June 2011 